Article

\title{
How Does Workplace Romance Influence Employee Performance in the Hospitality Industry?
}

\author{
Hyo Sun Jung ${ }^{1}$ and Hye Hyun Yoon ${ }^{2, *}$ \\ 1 Center for Converging Humanities, KyungHee University, Seoul 02447, Korea; chefcook@khu.ac.kr \\ 2 Department of Culinary Arts and Food Service Management, KyungHee University, Seoul 02447, Korea \\ * Correspondence: hhyun@khu.ac.kr
}

Received: 25 May 2020; Accepted: 6 July 2020; Published: 7 July 2020

check for updates

\begin{abstract}
With the aim of providing insights to scholars, administrators, and managers on how an employee's romantic involvement influences job engagement and performance, this study examined workplace romance as a psychological mechanism for determining job performance. A total of 224 deluxe hotel employees in South Korea participated in the research. The results indicate that workplace romance significantly affects employees' job engagement and performance. Employees who sustain a favorable and positive relationship with others in their organization eventually exhibit increased work effectiveness, which then exerts a constructive effect on hotel services and performance. Moreover, workplace romance experience can significantly improve the effect of workplace romance on job engagement. The paper also discusses limitations and future research directions.
\end{abstract}

Keywords: workplace romance; job engagement; job performance; deluxe hotel

\section{Introduction}

Many people meet and socialize in the workplace [1], which increases the potential for romantic involvement $[2,3]$. Workplace romance occurs when two people within an organization acknowledge romantic and sexual attraction to each other and act upon these emotions [4]. Sharing romantic feelings and forming a positive relationship with someone in such a setting can pave the way for employees' satisfaction within the organization [5]. However, despite the obvious considerable influence of romantic relationships on organizational performance (including employee behavior and efficacy), thus far, this issue has been underexplored in the domain of business administration. This topic has also been largely neglected in organizational behavior discourse [6]. For many decades, researchers focused on negative workplace phenomena, including employee stress, depression, and anxiety, formulating and proposing various approaches to mitigate these occurrences [7]. Similarly, a particularly unfavorable perception of romantic relationships in the workplace has been adopted, as attempts to break down the boundary between work and personal lives or pursue a romance are traditionally regarded as problems for an organization [8]. Such a standpoint is supported by social exchange theory, which maintains that employees might consider leaving the workplace as a result of disadvantageous social exchanges. Given the diverse views on workplace romance, discussing its organizational effects is a timely endeavor.

Existing research states that workplace romance induces both positive and negative effects (e.g., sense of hostility and decreased productivity) on employee behavior [6,9-11]. Quinn [12] suggested that workplace romance can contribute to both the improvement and deterioration of different behavioral and performance-related outcomes of employees and organizations. Dillard et al. [13] and Matthewman et al. [4] emphasized that love affairs between employees relate favorably to job performance. Aside from being a beneficial influence on employee behavior, workplace romance also engenders satisfaction with one's life [14]. Khan et al. [15] clarified that the workplace romance 
improves job performance when mediated by feelings of psychological wellbeing. In contrast, Harrison and Lee [9] emphasized that workplace romances have a negative rather than a positive influence on work performance. Willams et al. [10] noted that workplace romance negatively affects employees' behavior and performance, whereas Cole [16] observed that a workplace romance may act as a new stress factor in addition to an existing job stressors. Such a stressor could result in a person's morale being reduced by his/her workplace romance [17]. Most workplace romances that end eventually can cause emotional exhaustion, inadequate job performance, or job transfer [6]. Thus, these findings suggest that a romantic relationship may do harm to employees, their organizational behavior, and their long-term performance outcomes. In particular, when a romantic relationship ends, it may have negative synergy effects [2]. Thus far, there has been a lack of agreement on the connection between workplace romance and job performance in the studies conducted. This lack of consensus means that the connection between workplace romance and job performance has yet to be completely established.

Five-star hotels that are customer service-oriented belong to the labor-intensive service industry, which inevitably relies on employees' abilities and needs [18]. In deluxe hotels, the work environment is paramount to exploration in relation to romantic entanglements [19], as hotels are characterized by a vertical work structure and rigid organizational culture [20]. In addition, hotels are often described as facilities with unpleasant or poor working conditions characterized by monotonous tasks and strenuous work hours [21]. Therefore, romance can play the role of a "lubricant" in overcoming such a rigid and inflexible culture. Moreover, culture is a highly important element that forms individuals' thoughts, feelings, and behaviors [22]. In accordance with cultural dimensions theory proposed by Hofstede [23] and Reisinger and Crotts [24], South Koreans are characterized by a relatively collectivist culture and long-term orientation. Thus, we argue that the study of employees' perceptions of romance and behaviors will be significant within a culture characterized by self-consciousness, collective decision making, an increasing sense of solidarity between groups, and the establishment of long-term oriented relationships. Thus, on the basis of the argument that the destructive influence of workplace romances is grounded upon an outdated concept, which forces organizational control and the suppression of employees' emotions [25], the present study assumes that romances within an organization can produce practical and positive relationships.

Accordingly, we established job engagement and performance as positive variables that can explain job attitudes and proceeded with a study focusing on outcome variables. We also examined how the employees' romantic experiences influence their job engagement and performance on different levels. Moreover, to date, no study has examined workplace romance within the deluxe hotel industry; thus, we conducted this study with hotel employees as its subjects. Therefore, this study is meaningful and distinct from other studies in that it applies the concept of workplace romance to hotel workplaces. To the best of our knowledge, this is the first study to examine workplace romance in the context of employee participation and performance.

\section{Theoretical Background and Hypothesis Development}

\subsection{Hypothesis Development}

In the literature, only a limited number of studies have focused on the relationship between workplace romance and employees' job engagement. For example, Pierce et al. [3] stated that employees' job engagement increases, because workplace romances increase their willingness to work longer hours with their partners. Dillard and Broetzmann [26] observed that workplace romances increase employees' engagement with their jobs. Moreover, Shuck et al. [27] stated that employees' positive attitudes and perceptions toward workplace romance lead them to make additional efforts at work, thus increasing their active engagement. Doll and Rosopa [1] explained the positive effects of workplace romance based on Ajzen's theory [28,29], suggesting that when employees have positive attitudes toward workplace romance, organizational norms support such attitudes, and employees can control their behaviors (in the case of having a feasible romantic partner, for example). From a similar 
perspective, Ditzen et al. [30] stated that employees relieve their stress and maintain positive and optimistic conditions through the romances that they experience within their respective organizations. Ditzen and Heinrichs [31] noted that workplace romances provide a sense of stability and social inclusion while also reducing stress in the workplace. One study suggested that workplace romances can create positive energy and feelings through the emotional spillover effects [32], and another concluded that workplace romances become a positive force in organizational life by increasing mental energy [16]. In addition, those involved in workplace romances showed higher levels of enthusiasm for their work [13]. In a similar context, Anderson and Hunsaker [33] noted that employees can reduce stress and anxiety through workplace romances. Meanwhile, Pierce and Aguinis [17] argued that the positive emotions experienced by employees in romantic relations can have affective spillover effects in the form of emotional bonding with their organization and coworkers. Consequently, employees' perceptions of workplace romances are likely to increase their job engagement. Hence, the following hypothesis is established:

Hypothesis 1 (H1). Workplace romance positively influences employees' job engagement.

Many studies verified the positive relationship between employees' job engagement and their performance. For instance, Bakker and Bal [34] noted that engaged employees are likely to experience positive feelings, which can expand their cognitive skills even in complex situations, inevitably resulting in even higher levels of job performance [35]. Employees' job engagement can potentially predict their job performance, and employees with greater job engagement tend to engage in activities that enhance their organizational performance [36]. Dajani [37] reported that increased job engagement helped maximize job performance, and also Yongxing et al. [38] suggested a close link between job engagement and performance. While Ismail et al. [39] found that employees' higher levels of job engagement has a more significant impact on their job performance, Kim et al. [40] stated that employees attain higher levels of job performance when they engage in their work with great enthusiasm. Based on such information, the following hypothesis is proposed:

Hypothesis 2 (H2). Job engagement positively influences employees' job performance.

In a study related to workplace romance and job performance, Dillard et al. [13] asserted that employees' more positive perceptions of organizational romance result in higher levels of job performance. Pierce and Aguinis [17] noted that, because workplace romance is often perceived negatively by colleagues and managers, those who have positive attitudes toward workplace romance (or currently maintain one) want to impress their supervisors by improving their job competency. Such a tendency often leads to enhanced job performance [25]. Wright and Cropanzano [41] reported that employees exhibit positive job performance through workplace romances. Moreover, Matthewman et al. [4] concluded that workplace romances should not be entirely prohibited as they contribute to positive employee performance. Khan et al. [15] reported that workplace romances have highly positive effects on job performance, and such a positive relationship can be influential in service improvement by contributing to employees' psychological wellbeing. Moreover, employees' motives and desires for romance in an organization positively affect their job performance [3]. Biggs et al. [42] suggested that those involved in workplace romances mostly achieved desirable outcomes in the workplace. Debrot et al. [14] stated that employees' satisfaction with life increases through romantic relationships in the workplace and, once they become happy workers, they tend to exhibit a relatively improved performance in the organizational environment [43]. Finally, consensual and devoted romantic relationships in the workplace have a significant impact on employees' behavior and positive performance [44]. These results led to the development of the following hypothesis:

Hypothesis 3 (H3). Workplace romance positively influences employees' job performance. 
In relation to the advantages of romantic involvement at work, Warfield [45] noted that an employee's warm attraction toward someone else improves their productivity. Moreover, those who have engaged in workplace romances have more favorable attitudes toward productivity than those who have not experienced love in the workplace [26]. Debrot et al. [14] stated that romantic relationships in the workplace positively affect the behavior and life satisfaction of engaged employees, and once engaged in a romantic relationship, they are likely to experience its positive impact on their behaviors [46]. Meanwhile, Wright and Cropanzano [41] reported that employees involved in a workplace romance show improved job satisfaction and performance. Indeed, the satisfactory romantic experiences of those involved in workplace romances can have constructive effects on their psychological wellbeing [32]. Moreover, according to Simon and Barett [47] and Woodhouse et al. [48], romantic relationships in an organization reduce employees' depression and enhance their self-esteem and optimism. These findings support the notion that the experience of workplace romances further strengthens psychological relations in the workplace. Tengberg and Tidefors [49] suggested that most employees perceive workplace romances as positive experiences, which induce them to perform more positive behaviors in the organization. Khan et al. [15] stated that employees' emotions originating in workplace romances can develop into organizational achievements by stimulating their positive emotional conditions. Based on the results of these previous studies, the present study assumed that employees with workplace romance experiences would be able to perceive the positive effects of workplace romance more strongly than those without such experiences. Thus, the following hypothesis is proposed:

Hypothesis 4 (H4). The greater the employees' workplace romance experiences, the greater than influence between:

Hypothesis 4 (H4a). Workplace romance and job engagement;

Hypothesis $4 \mathbf{( H 4 b )}$. Job engagement and job performance;

Hypothesis 4 (H4c). Workplace romance and job performance.

\subsection{Research Model}

As shown in Figure 1, workplace romance, job engagement, job performance, and employees' romantic experiences are used as the independent, mediating, dependent, and moderating variables in this study, respectively. We tested the hypotheses that focus on the positive influence of workplace romance on job engagement and job performance. The study also examined the moderating effects of employees' romantic experiences on workplace romance as a whole. These presuppositions are presented in Figure 1.

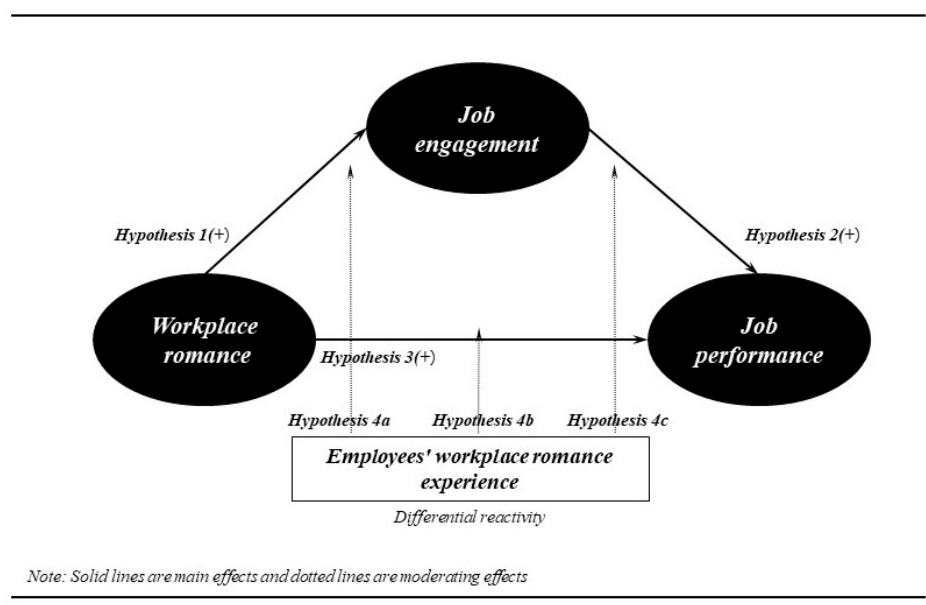

Figure 1. A proposed model of workplace romance, job engagement, job performance, and employees' romantic experiences. 


\section{Research Methodology}

\subsection{Samples and Procedures}

Data were collected over a period of one month by administering a survey to employees of 10 five-star hotels located in Seoul. The survey included respondents who acknowledged having romantic relationships with their coworkers. Each participant who voluntarily completed the survey was given a coffee coupon worth USD 5. A pilot test involving 30 employees was performed to guarantee the reliability of the scale, after which 257 questionnaires were distributed. The incomplete questionnaires were removed in the coding process, leaving us with 224 questionnaires for the final analysis (response rate $=87.15 \%$ ). Among the respondents, $62.1 \%$ indicated that they were currently involved in a romantic relationship in the workplace. Men and women accounted for $51.6 \%$ and $48.4 \%$ of the sample, respectively. The percentage of college graduates or those with lower levels of education was $42 \%$, and the percentage of university graduates was $64.7 \%$ ( $16.3 \%$ of whom had completed graduate school). Of the respondents, $35.7 \%$ worked in the back of house, whereas $64.3 \%$ were assigned to the front of house in the hotels.

\subsection{Instrument Development}

"Workplace romance" is an agreed-upon, dedicated romantic relationship between two individuals employed in the same organization or company [15]. It is also defined as a relationship of mutual welcome between two members of the same organization [26]. In this study, workplace romance, job engagement, and job performance were measured with an instrument comprising items rated on a seven-point Likert scale ranging from one (strongly disagree) to seven (strongly agree). We measured romantic relationships through seven questions formulated on the basis of Pierce's [32] study. These included such items as "Romantic relations foster better communication between the two workers involved" and "It is all right for someone to look for a dating or marriage partner at work", to name a few. We defined "job engagement" as an employee's positive work-related mental state, characterized by complete devotion and vitality [50]. We determined job engagement in this study by using four questions adapted from Schaufeli et al. [51,52]. These included such items as "I am proud of the work that I do" and "At my work, I feel bursting with energy", among others. We regarded "job performance" as the degree to which employees can achieve tasks and meet organizational goals or the results of such an achievement [53]. This study measured job performance with four questions based on the studies of Ang et al. [54] and Song and Chathoth [55]. These included such items as "I contribute more to the effectiveness of my work unit as compared to most people in the same unit" and "My job performance level is the highest", to name a few.

The initial questionnaire was partly revised based on the results of a pilot test before being back-translated from English to Korean; this process was completed to verify that the translated version did not deviate from the original in terms of meaning [56]. The back-translation procedure was as follows: (1) the author translated all research items into Korean; (2) an expert, who was proficient in both Korean and English, read the translated version and confirmed the correction of expression errors that may have occurred in the translation process by revising any ambiguous expressions; and (3) another author translated the resulting Korean translation into English again. This process helped check any semantic differences in the translated Korean questionnaire items from the original ones.

\subsection{Data Analysis}

The data collected for this study were analyzed using SPSS (Statistical Package for the Social Sciences) and AMOS (Analysis of Moment Structures). The analysis of the respondents' demographic characteristics and descriptive statistics were conducted along with the normality test, reliability test, and exploratory factor analysis (EFA). Harman's test and a multicollinearity test were used to test for common method bias (CMB). Then, the confirmatory factor analysis and reliability analysis were employed to test the validity and reliability of the variables, respectively. A correlation analysis 
was also conducted to identify whether the direction of measurement of items was in line with the study's hypotheses, all four of which were verified through structural equation modeling (SEM) and multi-group analysis. Given that the SEM can measure all paths simultaneously, not stepwise, it is considered a more comprehensive and effective method than stepwise regression analysis.

\section{Results}

\subsection{Measurement of Reliability and Validity}

Prior to the analysis, two tests were conducted to examine the errors related to $\mathrm{CMB}$, given that all variables were collected from the same participants [57]. First, the questions were subjected to the Harman test, after which EFA was carried out to determine response bias. The results showed that the response bias was not significant, as evidenced by the fact that the explanatory power of the first factor did not exceed $50 \%$. Second, dispersion inflation coefficients were examined, which generated values below 2.5, indicating the absence of multicollinearity. Although these findings do not entirely rule out the possibility of CMB errors, they are sufficient in eliminating the potential for a significant problem with the analytical process. Normally, data used for SEM are assumed to exhibit multivariate normality. The normality assessment for all the variables in this work registered kurtosis values within +2.58 , thus confirming multivariate normality at the $p<0.01$ level [58]. The confirmatory measurement models demonstrated the soundness of measurement properties $\left(\chi^{2}=162.881\right.$, goodness-of-fit index $(\mathrm{GFI})=0.912$, and root mean square residual $=0.054$, see Table 1$)$. All the standardized factor loading values were 0.8 or higher, and the $t$-values exceeded $18.0(p<0.001)$. Moreover, the average variance extracted was 0.5 or higher, the composite construct reliability was 0.8 or higher, and the Cronbach's alpha values were 0.9 or higher-all exceeding the standard recommended values $[59,60]$.

Table 1. Results of the convergent validity and reliability analyses.

\begin{tabular}{|c|c|c|c|}
\hline $\begin{array}{l}\text { Construct } \\
\text { (Cronbach's Alpha) }\end{array}$ & $\begin{array}{l}\text { Standardized } \\
\text { Loadings }\end{array}$ & $t$-Value & $\begin{array}{l}\text { AVE } \\
\text { CCR }\end{array}$ \\
\hline Workplace romance & & & 0.799 \\
\hline$(0.966)$ & & & 0.940 \\
\hline $\mathrm{WR}_{1}$ Romantic relations foster better communication between the two workers involved & 0.907 & fixed & \\
\hline $\begin{array}{l}\text { WR } 2 \text { Some romantic intimacy among coworkers can create a more harmonious work } \\
\text { environment }\end{array}$ & 0.883 & 20.546 & \\
\hline $\mathrm{WR}_{3}$ Any worker who directs romantic attention toward another should be reprimanded ${ }^{\circledR}$ & 0.896 & 21.325 & \\
\hline $\begin{array}{l}\text { WR } 4 \text { Organization ought to ignore romantically oriented behavior among coworkers as long } \\
\text { as it does affect productivity }\end{array}$ & 0.906 & 21.991 & \\
\hline $\mathrm{WR}_{5}$ I would never get romantically involved with a coworker & 0.891 & 21.007 & \\
\hline $\mathrm{WR}_{6}$ It is all right for someone to look for a dating or marriage partner at work & 0.901 & 21.609 & \\
\hline $\begin{array}{l}\text { WR } 7 \text { I would go along with romantically oriented behavior that was common in my } \\
\text { workplace }\end{array}$ & 0.880 & 20.365 & \\
\hline Job engagement & & & 0.749 \\
\hline$(0.922)$ & & & 0.879 \\
\hline $\mathrm{JE}_{1} \mathrm{I}$ am proud on the work that I do & 0.888 & fixed & \\
\hline $\mathrm{JE}_{2}$ At my work, I feel bursting with energy & 0.889 & 18.564 & \\
\hline $\mathrm{JE}_{3} \mathrm{I}$ am highly engaged in this job & 0.830 & 16.324 & \\
\hline $\mathrm{JE}_{4} \mathrm{I}$ really "throw" myself into my job & 0.855 & 17.246 & \\
\hline Job performance & & & 0.774 \\
\hline$(0.932)$ & & & 0.893 \\
\hline $\mathrm{JP}_{1}$ The quantity of my job accomplishments of the most & 0.862 & fixed & \\
\hline $\begin{array}{l}\mathrm{JP}_{2} \text { I contribute more the effectiveness of my work unit as compared to most people in the } \\
\text { same unit }\end{array}$ & 0.853 & 16.617 & \\
\hline $\mathrm{JP}_{3}$ My job performance level is the highest & 0.896 & 18.199 & \\
\hline $\mathrm{JP}_{4}$ The quantity of my job accomplishments of the best & 0.908 & 18.630 & \\
\hline
\end{tabular}

Note: average variance extracted (AVE); composite construct reliability $(\mathrm{CCR}) ; \chi^{2}=162.881(\mathrm{df}=87) p<0.001$; $\chi^{2} / \mathrm{df}=1.872$; Goodness of Fit Index $(\mathrm{GFI})=0.912$; Normed Fit Index (NFI) = 0.952; Tucker Lewis Index $(\mathrm{TLI})=0.972$; Comparative Fit Index (CFI) = 0.977; Incremental Fit Index (IFI) = 0.977; Root Mean Square Residual $($ RMR) = 0.054; Root Square Error of Approximation (RMSEA) $=0.063$. 


\subsection{SEM}

Prior to the verification of this study's hypotheses via SEM, the correlations among the measurement items were identified (Table 2). The results indicated that all items were positively related to the hypotheses. The fit of the SEM intended to test the hypotheses was also excellent $\left(\chi^{2}=162.881\right.$, $\chi^{2} / \mathrm{df}=1.872, \mathrm{GFI}=0.912$, and comparative fit index $=0.977$, see Table 3$)$. The analysis showed that workplace romance increased the employees' job engagement $(\beta=0.251)$ and performance $(\beta=0.442)$, thus supporting Hypotheses 1 and 3. Such results are consistent with those derived by Shuck et al. [27], who found that workplace romance enhanced employee job engagement, as well as Pierce and Aguinis [17], and Khan et al. [15], who emphasized the positive connection between workplace romance and job performance. Additionally, Hypothesis 2 was supported, because employees' job engagement had significant effects on their job performance $(\beta=0.327)$. This is consistent with the findings of Dajani [37] and Ismail et al. [39].

Table 2. Means, standard deviations, and correlation analyses.

\begin{tabular}{|c|c|c|c|c|c|c|c|c|c|}
\hline Construct & $\mathrm{M} \pm \mathrm{SD}$ & 1 & 2 & 3 & 4 & 5 & 6 & 7 & 8 \\
\hline 1. Gender & $1.48 \pm 0.50$ & 1 & & & & & & & \\
\hline 2. Age & $33.67 \pm 7.92$ & $-0.189 * *$ & 1 & & & & & & \\
\hline 3. Education level & $2.38 \pm 0.98$ & $-0.182 * *$ & -0.038 & 1 & & & & & \\
\hline 4. Romance period & $1.45 \pm 0.49$ & 0.093 & -0.065 & -0.133 * & 1 & & & & \\
\hline 5. Positon & $1.25 \pm 0.85$ & -0.043 & 0.124 * & -0.007 & $-0.110 *$ & 1 & & & \\
\hline 6. Workplace romance & $4.80 \pm 1.22$ & $-0.135 *$ & 0.042 & 0.137 * & $-0.663^{* *}$ & $0.216^{* *}$ & 1 & & \\
\hline 7. Job engagement & $4.56 \pm 1.15$ & $-0.119 *$ & 0.098 & 0.222 ** & $-0.247^{* *}$ & 0.061 & $0.234^{* *}$ & 1 & \\
\hline 8. Job performance & $5.09 \pm 1.16$ & $-0.122 *$ & 0.095 & $0.211^{* *}$ & $-0.377^{* *}$ & 0.110 & $0.494^{* *}$ & $0.406^{* *}$ & 1 \\
\hline
\end{tabular}

Note: All variables were measured on a seven-point Likert scale from one (strongly disagree) to seven (strongly agree); Standard Deviation (SD); ${ }^{* *} p<0.01,{ }^{*} p<0.05$.

Table 3. Structural parameter estimates.

\begin{tabular}{lccc}
\hline \multicolumn{1}{c}{$\begin{array}{c}\text { Hypothesized Path } \\
\text { (Stated as Alternative Hypothesis) }\end{array}$} & $\begin{array}{c}\text { Standardized } \\
\text { Path Coefficients }\end{array}$ & $\boldsymbol{t}$-Value & Results \\
\hline H1: Workplace romance $\rightarrow$ Job engagement & 0.251 & $3.579^{* * *}$ & Supported \\
H2: Job engagement $\rightarrow$ Job performance & 0.327 & $6.889^{* * *}$ & Supported \\
H3: Workplace romance $\rightarrow$ Job performance & 0.442 & $5.157^{* * *}$ & Supported \\
\hline Goodness-of-fit statistics & $\chi^{2}=162.881(p<0.001)$ & \\
& $\mathrm{df}=87$ & \\
& $\chi^{2} / \mathrm{df}=1.872$ & \\
& $\mathrm{GFI}=0.912$ & \\
& $\mathrm{NFI}=0.952$ & \\
& $\mathrm{CFI}=0.977$ & \\
& $\mathrm{IFI}=0.977$ & \\
& $\mathrm{RMSEA}=0.063$ & \\
\hline
\end{tabular}

Note: ${ }^{* * *} p<0.001$.

\subsection{Moderating Effect}

In this study, four hypotheses were established based on the prediction that employees' perceptions of workplace romance, depending on their experience of it, can have varying levels of positive influence on job engagement and performance. Before analyzing the moderating effect in Hypothesis 4, measurement invariability depending on the level of employees' romantic experience was checked, which is shown in Table 4 . In the analysis results, the configural invariance model was significantly superior to the metric invariance model in two variables. It was confirmed that the factor-loading invariance of the two variables used in this study caused no problems. Hence, the moderating effect of employees' romantic experience in the organic causal relationship among workplace romance, job engagement, and job performance was tested based on multiple-group analysis. To verify the moderating effects of employees' romantic experiences, constrained and unconstrained models were 
compared, and the statistical significance level was set using differences in the degree of freedom (Table 5). According to the analysis results, job engagement had a more positive influence on those who had workplace romances than those who did not; therefore, Hypothesis 4a was supported. A statistically significant between-group difference of employees' romantic experiences was observed based on the chi-square of the two models $\left(\Delta \times 2[\mathrm{df}=1]=5.97>\Delta \chi^{2}[\mathrm{df}=1]=3.84\right)$. In terms of workplace romance and on the job engagement, a group with workplace romance experiences (beta $=0.264 ; t$-value $=2.548, p<0.05)$ showed a significantly higher outcome than a group with no experience of romance (beta $=0.153, t$-value $=1.527, p<0.05$ ). This finding suggests that employees' practical experiences of romantic involvement in the workplace tend to increase their job engagement. However, no significant moderating effects were found in the relationships between job engagement and job performance and between workplace romance and job performance; thus, Hypotheses $4 \mathrm{~b}$ and $4 c$ were rejected. Despite the absence of significant differences, the employees who had an experience of romance affairs in the workplace showed a relatively larger influence of increasing job performance through romance, compared to those who did not have such experiences. Consequently, the influence of employees' perceptions of workplace romance on their job engagement was stronger among those with a workplace romance experience than those without such an experience.

Table 4. Model fit indices of employees' romantic experience groups.

\begin{tabular}{cccccccc}
\hline & & $\chi^{2}$ & $d f$ & CFI & RMSEA & RMR & $\Delta \chi^{2}$ \\
\hline Romantic & Configural invariance model & 307.271 & 174 & 0.948 & 0.059 & 0.077 & $23.263 *$ \\
experience groups & Metric invariance model & 330.534 & 186 & 0.916 & 0.060 & 0.086 & 2.00 \\
\hline
\end{tabular}

Note: $\Delta \mathrm{df}=12, \Delta \chi^{2}=21.026(p<0.05)$; Root Mean Square Residual (RMR).

Table 5. Moderating effects of employees' romantic experiences.

\begin{tabular}{|c|c|c|c|c|c|c|c|}
\hline & \multicolumn{2}{|c|}{$\begin{array}{c}\text { No } \\
(\mathrm{N}=101)\end{array}$} & \multicolumn{2}{|c|}{$\begin{array}{c}\text { Yes } \\
(\mathrm{N}=120)\end{array}$} & \multirow{2}{*}{$\begin{array}{c}\text { Unconstrained } \\
\text { Model } \\
\text { Chi-Square } \\
\text { (df = 174) }\end{array}$} & \multirow{2}{*}{$\begin{array}{c}\text { Constrained } \\
\text { Model } \\
\text { Chi-Square } \\
(\text { df }=175)\end{array}$} & \multirow{2}{*}{$\begin{array}{c}\Delta \chi^{2} \\
(\mathrm{df}=1)\end{array}$} \\
\hline & $\begin{array}{l}\text { Standardized } \\
\text { Coefficients }\end{array}$ & $t$-Value & $\begin{array}{l}\text { Standardized } \\
\text { Coefficients }\end{array}$ & $t$-Value & & & \\
\hline $\mathrm{H} 4 \mathrm{a} \mathrm{WR} \rightarrow \mathrm{JE}$ & 0.153 & 1.527 * & 0.264 & $2.548 *$ & 307.271 & 311.412 & 4.141 * \\
\hline $\mathrm{H} 4 \mathrm{~b} \mathrm{JE} \rightarrow \mathrm{JP}$ & 0.242 & $2.471 *$ & 0.403 & $4.282^{* * *}$ & 307.271 & 308.253 & 0.982 \\
\hline $\mathrm{H} 4 \mathrm{c} \mathrm{WR} \rightarrow \mathrm{JP}$ & 0.333 & $3.241^{* * *}$ & 0.353 & $3.750 * * *$ & 307.271 & 308.803 & 1.532 \\
\hline
\end{tabular}

Note: $\chi^{2} / \mathrm{df}=1.766$; GFI $=0.848 ; \mathrm{NFI}=0.889 ; \mathrm{CFI}=0.948$; RMSEA $=0.059 ;{ }^{*} p<0.05 ;{ }^{* *} p<0.01 ;{ }^{* * *} p<0.001$; workplace romance (WR); job engagement (JE); job performance (JP).

\section{Discussion and Implications}

\subsection{Discussion of Results}

Romances that inevitably occur within an organization are an important factor that can influence various employee attitudes, such as motivation, job satisfaction, loyalty, and performance. However, from an academic perspective, workplace romances have been dismissed as a negligible element of organizational life. By focusing on the positive effects of workplace romances experienced by deluxe hotel employees, the present study attempted to clarify whether or not workplace romances increased job engagement and performance. Indeed, workplace romances had demonstrably positive impacts on employees' job engagement and performance, and such a positive influence on employees' job engagement was stronger among those with workplace romance experiences.

\subsection{Theoretical and Practical Implications}

The implications inferred from this study are as follows. First, the research is a preliminary attempt to investigate the causal relationship between hotel employees' romances and their job engagement and performance. Thus far, most research on workplace romance has involved employees outside the domain of hospitality (e.g., doctors, graduate students, and full-time employees, etc.), and none 
has looked into deluxe hotels wherein the services rendered by employees are the most important indicator of performance. The present work is meaningful, because it provides experiential evidence of the correlation between workplace romance and employee engagement and performance. Particularly, maintaining the psychological stability of employees at five-star hotels is highly important, because they experience frequent conflicts arising from emotional and stressful working conditions as well as the execution of unexpected tasks [61]. Eventually, these specific job characteristics of the hotel industry may enable employees to gain psychological stability through romantic relationships in the workplace, which can subsequently induce their positive behaviors. The positive influence of romantic involvement on the aforementioned employees' behaviors underlines the importance of romance within an organization and the benefits that it can generate within the organization. Moreover, we find that experiencing workplace romances significantly increased employees' job engagement. This result implies that romantic affairs in the workplace improve the employees' psychological wellbeing and self-esteem, which further increases their engagement as it boosts their positive belief in work. This outcome further confirms the positive influence of workplace romances. Presumably, this importance stems from the fact that the present society is characterized by a rising proportion of unmarried employees and declining marriage rates; thus, employees are more confident about seeking romance in the workplace and worry less about concealing it [32]. Moreover, compared to Western individualism, the Eastern collectivist culture promotes rather rigid aspects of employees' romantic relationships [22,62]. However, today's Eastern countries have opened the door to Western culture and achieved rapid economic development. As a result, workers lead their working lives within wider social networks, and workplace romances are now being considered more positively as channels that can generate beneficial outcomes for the organizations.

This study achieved its fundamental goal of encouraging a consideration of the advantages presented by workplace romances. Workplace romance should, therefore, not be perceived as a serious problem, at least in terms of its effect on employees' job engagement and performance. Managers need not take strict measures to forbid such relationships as long as the employees involved do not violate ethical and legal standards. The efforts of employees to sustain favorable connections with others in the organization are expected to eventually increase job performance levels, which can then constructively affect hotel service and performance [42]. Given that human resources are critical in the hotel industry, employees must participate in beneficial social exchanges. In relation to this, one useful strategy is to create an organizational environment that regards workplace romance as a natural part of the work; this can even serve as an internal marketing tool that strengthens communication among employees. If the increase in social bonds stimulates the creativity of employees, it could lead to an improvement in human services (e.g., developing new menus or improving service quality), resulting in steady increases in hotel performance. Notably, the absence of a policy that regulates workplace romances or the existence of an ambiguous policy does not exert a negligible effect on the workplace [4]. It is not desirable to strictly prohibit or control workplace romances or dates because it may encourage members to have a secret culture, thereby incurring unproductive consequences. Thus, it is necessary to have a clear policy about acceptable behaviors in organizations and control the relationship. Thus, organizations that are interested in managing office romances should implement a considerate policy that employees can accept, because this can encourage positive employee behavior and ultimately improve organizational performance. If employees feel that their organizations are receptive to romantic relationships at work, they may feel more engaged with their jobs and espouse a stronger sense of responsibility. To do this, a flexible organizational culture, rather than a coercive one, should be implemented. Such results are possible, because engagement may be sufficiently changed in the process of socialization. Given that opportunities for lifetime jobs have disappeared, an openness to workplace romances at the organizational level may be a crucial strategy to elevate employees' job engagement and performance. 


\subsection{Limitations and Future Research}

As with any other study, the present research is encumbered by certain limitations and its preliminary nature. First, the sample was confined to employees of deluxe hotels located in Seoul; thus, the results may differ from those obtained using samples from other cultural areas. Future research should, therefore, be conducted in various contexts to improve our understanding of how workplace romance contributes to positive job performance. Scholars should also investigate other variables that mediate the advantages of workplace romance (e.g., experience itself of romantic relationships, employees' personality, and employees' marital status, among others). Second, the questionnaires in this study were self-reported. Thus, future investigations could administer a survey proctored by supervisors or coworkers so as to prevent privacy and ethical standards violations. Third, the theoretical basis for the positive influence of workplace romance on organizational performance is lacking, because the number of existing studies is insufficient. Fourth, the influence of workplace romance on employee behaviors in the organization are likely to differ by national culture. Therefore, future studies can consider South Korea's cultural differences from Western countries. Finally, due to the small number of previous studies on workplace romance, the scope of the comparative analysis of research outcomes was limited. As an early exploration emphasizing the importance of workplace romance, this study is expected to stimulate future research that empirically demonstrates both the positive and negative effects of workplace romance in the hospitality industry.

Author Contributions: The authors contributed equally to this work. All the authors contributed to the conceptualization, formal analysis, investigation, methodology, writing of the original draft, and review and editing. All authors have read and agreed to the published version of the manuscript.

Funding: This research received no external funding

Conflicts of Interest: The authors declare no conflict of interest.

\section{References}

1. Doll, J.; Rosopa, P.J. Workplace romances: Examining attitudes experience, conscientiousness, and policies. J. Manag. Psychol. 2015, 30, 439-453. [CrossRef]

2. Mainiero, L.A. Coping with powerlessness: The relationship of sex and job dependency to empowerment strategy usage. Admin. Sci. Q. 1986, 31, 633-653. [CrossRef]

3. Pierce, C.A.; Byrne, D.; Aguinis, H. Attraction in organizations: A model of workplace romance. J. Org. Behav. 1996, 17, 5-32. [CrossRef]

4. Karl, K.A.; Sutton, C.L. An examination of the perceived fairness of workplace romance policies. J. Bus. Psychol. 2000, 14, 429-442. [CrossRef]

5. Gächter, S.; Fehr, E.; Kment, C. Does social exchange increase voluntary cooperation? Kyklos 1996, 49, 541-554. [CrossRef]

6. Willson, F. Romantic relationships at work: Why love can hurt. Int. J. Manag. Rev. 2015, 17, 1-19. [CrossRef]

7. Singh, S.; David, R.; Mikkilineni, S. Organizational virtuousness and work engagement: Mediating role of happiness in India. Adv. Dev. Hum. Res. 2018, 20, 88-102. [CrossRef]

8. Baker, A.N. Antecedents and consequences of observing workplace sexual behavior. J. Manag. Psychol. 2016, 31, 265-279. [CrossRef]

9. Harrison, R.; Lee, R. Love at work. J. Personal. Soc. Psychol. 1986, 1, $20-24$.

10. Williams, C.L.; Guiffre, P.A.; Dellinger, K. Sexuality in the workplace: Organisational control, sexual harassment, and the pursuit of pleasure. Annu. Rev. Soc. 1999, 25, 73-93. [CrossRef]

11. Pierce, C.A.; Aguinis, H. Moving beyond a legal-centric approach to managing workplace romances: Organizationally sensible recommendations for HR leaders. Hum. Res. Manag. 2009, 48, 447-464. [CrossRef]

12. Quinn, R.E. Coping with Cupid: The formation, impact and management of romantic relationships in organizations. Admin. Sci. Q. 1977, 22, 30-45. [CrossRef]

13. Dillard, J.P.; Hale, J.L.; Segrin, C. Close relationships in task environments: Perceptions of relational types, illicitness, and power. Manag. Commun. Q. 1994, 7, 227-255. [CrossRef] 
14. Debrot, A.; Schoebi, D.; Perrez, M.; Horn, A.B. Touch as an interpersonal emotion regulation process in couples' daily lives: The mediating role of psychological intimacy. Personal. Soc. Psychol. Bull. 2013, 39, 1373-1385. [CrossRef] [PubMed]

15. Khan, M.A.S.; Jianguo, D.; Usman, M.; Ahmad, M.K. Moderated mediation model of interrelations between workplace romance, wellbeing, and employee performance. Front. Psychol. 2017, 8, 2158. [CrossRef]

16. Cole, N. Workplace romance: A justice analysis. J. Bus. Psychol. 2009, 24, 363-372. [CrossRef]

17. Pierce, C.A.; Aguinis, H. Romantic relationships in organizations: A test of a model of formation and impact factors. Manag. Res. 2003, 1, 161-169. [CrossRef]

18. King, C. One size doesn't fit all: Tourism and hospitality employees' response to internal brand management. Int. J. Contemp. Hosp. Manag. 2010, 22, 517-534. [CrossRef]

19. Manning, M.L.; Davidson, M.; Manning, R.L. Measuring tourism and hospitality employee workplace perceptions. Int. J. Hosp. Manag. 2008, 24, 75-90. [CrossRef]

20. Pienaar, J.; Willemse, S.A. Burnout, engagement, coping and general health of service employees in the hospitality industry. Tour. Manag. 2008, 29, 1053-1063. [CrossRef]

21. Lucas, R. Industrial relations in hotels and catering: Neglect and paradox. Br. J. Ind. Relat. 1996, 34, $267-286$. [CrossRef]

22. Dion, K.K.; Dion, K.L. Individualistic and collectivistic perspectives on gender and the cultural context of love and intimacy. J. Soc. Issues 1993, 49, 53-69. [CrossRef]

23. Hofstade, G.J. Adoption of communication technologies and national culture. Syst. Inf. Manag. 2001, 6, 55-74.

24. Reisinger, Y.; Crotts, J.C. Applying Hofstede's national culture measures in tourism research: Illuminating issues of divergence and convergence. J. Travel Res. 2010, 49, 153-164. [CrossRef]

25. Balaban, R.V. Romance at work and the negative impact it has on the workplace environment. J. Pub. Admin. Fin. Law 2019, 15, 127-134.

26. Dillard, J.P.; Broetzmann, S.M. Romantic relationships at work: Perceived changes in job-related behaviours as a function of participant's motive, partner's motive and gender. J. Appl. Soc. Psychol. 1989, 19, 93-110. [CrossRef]

27. Shuck, B.; Owen, J.; Manthos, M.; Quirk, K.; Rhoades, G. Co-workers with benefits: The influence of commitment uncertainty and status on employee engagement in romantic workplace relationships. J. Manag. Dev. 2016, 35, 382-393. [CrossRef]

28. Ajzen, I. From intentions to actions: A theory of planned behavior. In Action Control: From Cognition to Behavior; Kuhi, J., Beckmann, J., Eds.; Springer: Berlin/Heidelberg, Germany, 1985; pp. 11-39.

29. Ajzen, I. The theory of planned behavior. Organ. Behav. Hum. Dec. Process. 1991, 50, 179-204. [CrossRef]

30. Ditzen, B.; Neurmann, I.D.; Bodenmann, G.; Turner, R.A.; Ehlert, U.; Heinrichs, M. Effects of different kinds of couple interaction on cortisol and heart rate responses to stress in women. Psychoneuroendocrinology 2007, 32, 565-574. [CrossRef]

31. Ditzen, B.; Heinrichs, M. Psychobiology of social support: The social dimension of stress buffering. Restor. Neurol. Neurosci. 2014, 32, 149-162. [CrossRef]

32. Pierce, C.A. Factors associated with participating in a romantic relationship in a work environment. J. Appl. Soc. Psychol. 1998, 28, 1712-1730. [CrossRef]

33. Anderson, C.I.; Hunsaker, P.L. Why there's romancing at the office and why it's everyone's problem. Pers. J. $1985,62,57-63$.

34. Bakker, A.B.; Bal, P. Weekly work engagement and performance: A study among starting teachers. J. Occup. Organ. Psychol. 2010, 83, 189-206. [CrossRef]

35. Fredrickson, B.L. The role of positive emotions in positive psychology: The broaden-and-build theory of positive emotions. Am. Psychol. 2010, 56, 218-226. [CrossRef]

36. Rich, B.L.; Lepine, J.A.; Crawford, E.F. Job engagement: Antecedents and effects on job performance. Acad. Manag. J. 2010, 53, 617-635. [CrossRef]

37. Dajani, M.A.Z. The impact of employee engagement on job performance and organizational commitment in the Egyptian banking sector. J. Bus. Manag. Sci. 2015, 3, 138-147. 
38. Yongxing, G.; Hongfei, D.; Baoguo, X.; Lei, M. Work engagement and job performance: The moderating role of perceived organizational support. Ann. Psychol. 2017, 33, 708-713. [CrossRef]

39. Ismail, H.N.; Iqbal, A.; Nasa, L. Employee engagement and job performance in Lebanon: The mediating role of creativity. Int. J. Prod. Perform. Manag. 2019, 68, 506-523. [CrossRef]

40. Kim, W.; Han, S.J.; Park, J. Is the role of work engagement essential to employee performance or nice to have? Sustainability 2019, 11, 1050. [CrossRef]

41. Wright, T.A.; Cropanzano, R. The happy/productive worker thesis revisited. J. Happiness Stud. 2007, 26, 269-307. [CrossRef]

42. Biggs, D.; Matthewman, L.; Fultz, C. Romantic relationships in organizational settings. Gend. Manag. Int. J. 2012, 27, 271-285. [CrossRef]

43. Judge, T.A.; Thoresen, C.J.; Bono, J.E.; Patton, G.K. The job satisfaction-job performance relationship: A qualitative and quantitative review. Psychol. Bull. 2001, 127, 376-407. [CrossRef] [PubMed]

44. Khan, M.A.S.; Jianguo, D.; Hameed, A.A.; Mushtaq, T.U.L.; Usman, M. Affective commitment foci as parallel mediators of the relationship between workplace romance and employee job performance: A cross-cultural comparison of the people's Republic of China and Parkistan. Psychol. Res. Behav. Manag. 2018, 11, 267-278. [CrossRef] [PubMed]

45. Warfield, A. Co-worker Romances: Impact on the work group and on career oriented women. Pers. J. 1987, 64, 22-35.

46. Koole, S.L.; Sin, M.T.A.; Schneider, I.K. Embodied terror management: Interpersonal touch alleviates existential concerns among individuals with low self-esteem. Psychol. Sci. 2014, 25, 30-37. [CrossRef]

47. Simon, R.W.; Barrett, A.E. Nonmarital romantic relationships and mental health in early adulthood: Does the association differ for women and men? J. Health Soc. Behav. 2012, 51, 168-182. [CrossRef]

48. Woodhouse, S.S.; Dykas, M.J.; Cassidy, J. Loneliness and peer relations in adolescence. Soc. Dev. 2012, 21, 273-293. [CrossRef]

49. Tengberg, L.G.W.; Tidefors, I. Workplace romances: Going to work is amazing and really fun. Int. J. Psychol. Stud. 2016, 8, 84-97.

50. Schaufeli, W.B.; Salanova, M.; Gonzalez-Roma, V.; Bakker, A.B. The measurement of engagement and burnout: A confirmative analytic approach. J. Happiness Stud. 2002, 3, 71-92. [CrossRef]

51. Schaufeli, W.; Bakker, A.B. Job demands, job resources, and their relationship with burnout and engagement: A multi-sample study. J. Org. Behav. 2004, 25, 293-315. [CrossRef]

52. Schaufeli, W.B.; Bakker, A.B.; Salanova, M. The measurement of work engagement with a short questionnaire: A cross-national study. Educ. Psychol. Meas. 2006, 66, 701-716. [CrossRef]

53. Griffin, M.A.; Neal, A.; Parker, S.K. A new model of work role performance: Positive behavior in uncertain and interdependent contexts. Acad. Manag. J. 2007, 50, 327-347. [CrossRef]

54. Ang, S.; Van Dyne, L.; Begley, T.M. The employment relationships of foreign workers versus local employees: A field study of organizational justice, job satisfaction, performance, and OCB. J. Org. Behav. 2003, 24, 561-583. [CrossRef]

55. Song, Z.; Chathoth, P.K. Core self-evaluations and job performance: The mediating role of employees' assimilation-specific adjustment factor. Int. J. Hosp. Manag. 2003, 33, 240-249. [CrossRef]

56. Brislin, R.W. Translation and content analysis of oral and written material. In Handbook of Cross-Cultural Psychology: Methodology; Triandis, H.C., Berry, J.W., Eds.; Allyn and Bacon: Boston, MA, USA, 1980; pp. 389-444.

57. Podsakoff, K.J.; MacKenzie, S.B.; Lee, J.Y.; Podsakoff, N.P. Common method biases in behavioral research: A critical review of the literature and recommended remedies. J. Appl. Psychol. 2003, 88, 879-903. [CrossRef]

58. Muthen, B.O.; Kaplan, D. A comparison of methodologies for the factor analysis of nonnormal Likert variables. Br. J. Math. Stat. Psychol. 1985, 38, 171-189. [CrossRef]

59. Bagozzi, R.; Yi, Y. On the evaluation of structural equation models. J. Acad. Mark. Sci. 1998, 16, 74-94. [CrossRef]

60. Gerbing, D.W.; Anderson, J.C. An updated paradigm for scale development incorporating unidimensionality and its assessment. J. Mark. Res. 1988, 25, 186-192. [CrossRef] 
61. Ariza-Montes, A.; Arjona-Fuentes, J.M.; Han, H.; Law, R. Work environment and well-being of different occupational groups in hospitality: Job demand-control-support model. Int. J. Hosp. Manag. 2018, 73, 1-11. [CrossRef]

62. Simmons, C.H.; Vom Kolke, A.; Shimizu, H. Attitudes toward romantic love among American, German, and Japanese students. J. Soc. Psychol. 1986, 126, 327-336. [CrossRef] 